\title{
Experimental investigation of post-dryout heat transfer in annuli with flow obstacles
}

\author{
Ionut Gheorghe Anghel*, Henryk Anglart, Stellan Hedberg \\ Nuclear Reactor Technology, School of Engineering Sciences, Royal Institute of Technology (KTH), Roslagstullsbacken 21, SE-10691 Stockholm, Sweden
}

\section{A R T I C L E I N F O}

\section{Article history:}

Received 7 April 2011

Received in revised form 4 August 2011

Accepted 5 August 2011

\begin{abstract}
A B S T R A C T
An experimental study on post-dryout heat transfer was conducted in the High-pressure WAter Test (HWAT) loop at the Royal Institute of Technology in Stockholm, Sweden. The objective of the experiments was to investigate the influence of flow obstacles on the post-dryout heat transfer. The investigated operational conditions include mass flux equal to $500 \mathrm{~kg} / \mathrm{m}^{2} \mathrm{~s}$, inlet sub-cooling $10 \mathrm{~K}$ and system pressure 5 and $7 \mathrm{MPa}$. The experiments were performed in annuli in which the central rod was supported with five pin spacers. Two additional types of flow obstacles were placed in the exit part of the test section: a cylinder supported on the central rod only and a typical BWR grid spacer cell. The measurements indicate that flow obstacles improve heat transfer in the boiling channel. It has been observed that the dryout power is higher when additional obstacles are present. In addition the wall temperature in post-dryout heat transfer regime is reduced due to increased turbulence and drop deposition. The present data can be used for validation of computational models of post-dryout heat transfer in channels with flow obstacles.
\end{abstract}

(c) 2011 Elsevier B.V. All rights reserved.

\section{Introduction}

A forced convection heat transfer to a two-phase mixture consisting of the continuous vapour phase and the dispersed liquid phase, when the liquid film on the heater walls is no longer supported, is termed here as the post-dryout heat transfer regime. Other names used in the literature to refer to this type of heat transfer are post-CHF (post-critical heat flux), mist flow or dispersed-flow film boiling (DFFB). One of the characteristic features of post-dryout heat transfer is a dramatic reduction of the heat transfer coefficient, and thus a significant increase of the heater wall temperature, as compared to the conditions before the onset of dryout.

The main goal of the present work is to investigate the influence of flow obstacles on the intensity of post-dryout heat transfer at conditions relevant to Boiling Water Reactors (BWR) applications. During the normal operation of BWR the onset of dryout is precluded due to sufficiently high safety margins. However, during a BWR start-up, when the coolant flow through the reactor core is relatively low and the reactor power is high enough, core power

\footnotetext{
* Corresponding author. Tel.: +46 855378888.

E-mail addresses: iganghel@kth.se (I.G. Anghel), henryk@kth.se (H. Anglart), stellan@energy.kth.se (S. Hedberg).
}

and flow instability may occur. During such power and flow oscillations short-term post-dryout conditions might occur in some fuel rod assemblies. For safety reasons is thus important to predict the time history of the clad wall temperature to evaluate its integrity. Needless to say that such predictions require knowledge of the heat transfer coefficient at given conditions and taking into account the geometry details of fuel assemblies, in particular, the influence of spacer grids.

Post-dryout heat transfer has been investigated during the past several decades and experimental data have been obtained in both simple tubes and in rod bundles (e.g. Koizumi et al., 1987; Moon et al., 2005; Tuzla et al., 1992). The influence of flow obstacles on post-dryout heat transfer at BWR conditions was investigated in an annular test section with a single spacer grid cell and a significant improvement of heat transfer coefficient was reported (Anglart and Persson, 2007). The present experiments employ an annular test section in which the inner rod is supported with pin spacers, and two additional flow obstacles are inserted to measure their net effect on the post-dryout heat transfer. The test section has been instrumented with 88 thermocouples to allow for a significant improvement of the accuracy of measurements, as described in Anghel et al. (2010). Due to the high accuracy of measurements and thanks to the performed analysis of error propagation, the present measurements are suitable for validation of computational models of post-dryout heat transfer. 


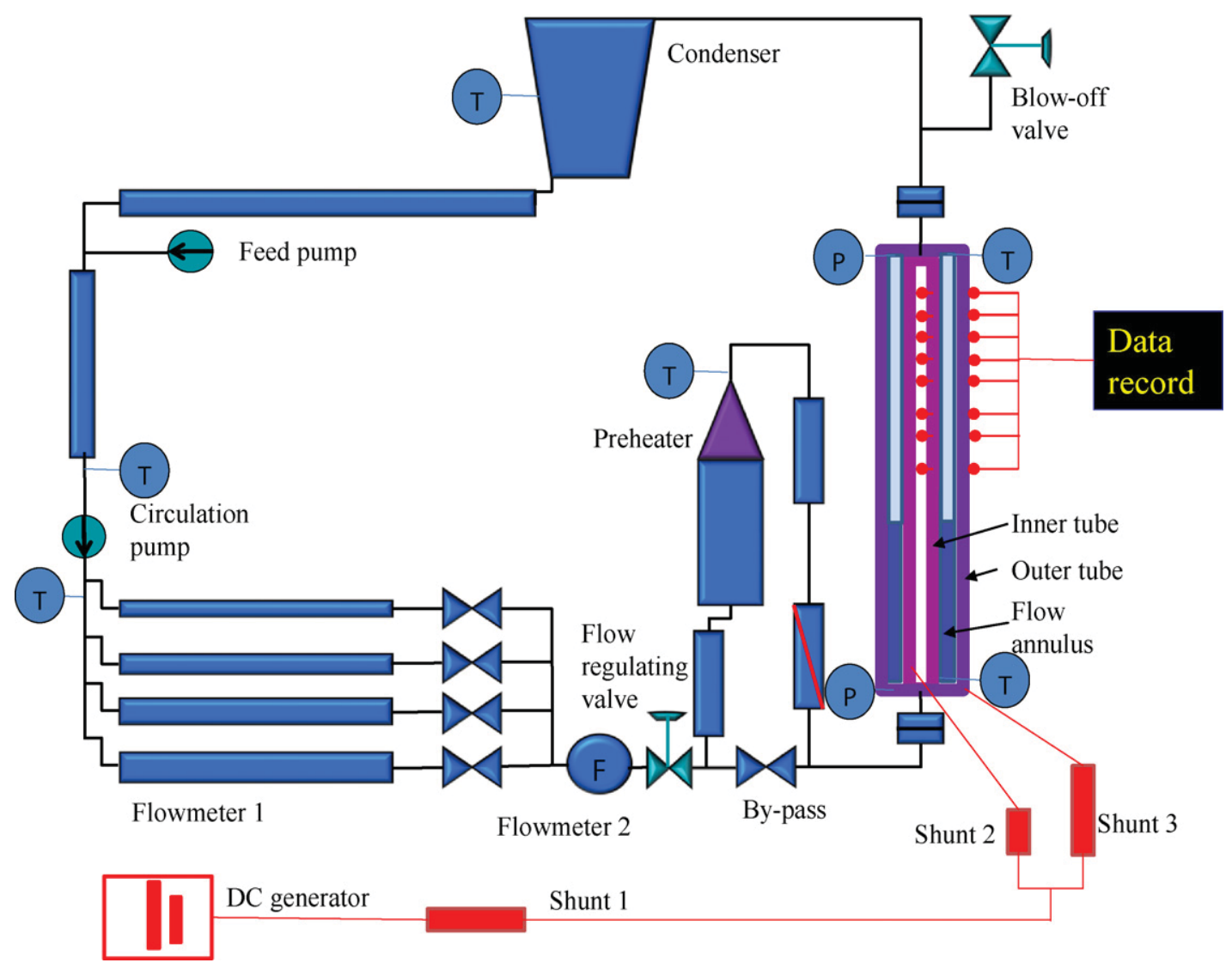

Fig. 1. The High-pressure WAter Test (HWAT) loop.

\section{Experimental facility}

\subsection{The loop}

The High-pressure WAter Test (HWAT) loop used for the postdryout experiments was designed to operate at pressures up to $25 \mathrm{MPa}$. All parts in contact with water (except the test section) are made of stainless steel. The loop construction allows for test sections up to $7 \mathrm{~m}$ in length. In Fig. 1a simplified flow diagram of the loop is presented.

The main components of the loop are: feed water pump, circulation pump, flow measurement system, automatic flow control valve, pre-heater, test section, condenser and blow-off valve. A secondary circuit with coolant water at $293.15 \mathrm{~K}$ is used to cool the circulation pump.

The loop is operating as follows. The circulation water first has to pass through the flow measurement system. From here water flows to the $155 \mathrm{~kW}$ pre-heater, which is needed to adjust the inlet temperature to the test section. Later on, subcooled water enters into the test section. After the test section, the water-steam mixture is passing through the condenser.

The water circulation in the loop is provided by the circulation pump, which has a pressure head of $100 \mathrm{~m}$ water, a big part of this being used in the duct system between the pump and the test section to secure a stable operation of the loop.

\subsection{Test section}

The test section consists of $12.7 \mathrm{~mm} \times 24.3 \mathrm{~mm} \times 3650 \mathrm{~mm}$ annulus assembled from two concentric pipes. In the present work the inner pipe is referred to as a rod while the outer pipe is referred to as a tube. Both the rod and the tube are manufactured from
Inconel 600. This material had been chosen because of the small rate of change of the resistivity with the temperature (Inconel 600). The design pressure and temperature for the test section are $18.3 \mathrm{MPa}$ and $973 \mathrm{~K}$, respectively.

Two copper rings, $0.1 \mathrm{~m}$ long each, were soldered on both the rod and the tube. In the present paper the distance between the copper rings is referred to as the heated length. The electrical power was supplied via two copper electrodes connected to the copper rings. In order to keep heat losses at an insignificant level, $90 \mathrm{~mm}$ thick glass fibre insulation was mounted around the test section. Nevertheless, for calculation of the heat flux all the heat losses were taken into account.

The experiments were conducted in three different test sections: a test section with pin spacers only denoted as test section A, a test section with pin spacers and cylindrical obstacles denoted as test section B, a test section with pin spacers and grid obstacles denoted as test section $\mathrm{C}$. The following operational conditions were employed in the experiments: inlet mass flux equal to $500 \mathrm{~kg} / \mathrm{m}^{2} \mathrm{~s}$, inlet sub-cooling equal to $10 \mathrm{~K}$ and system pressure 5 and $7 \mathrm{MPa}$.

The blockage area of the flow obstacles is: $10.13 \%$ in case of pin spacers, $7.3 \%$ in case of cylindrical obstacles and $10.07 \%$ in case of grid obstacles. The heated length of all three test sections together with pin spacers and flow obstacles used in the experiment is presented in Fig. 2.

\subsection{Temperature measurements}

To control the operating conditions of the loop operation during experiments, the temperature at seven locations must be measured on the continuous basis. The thermocouples employed for the fluid 


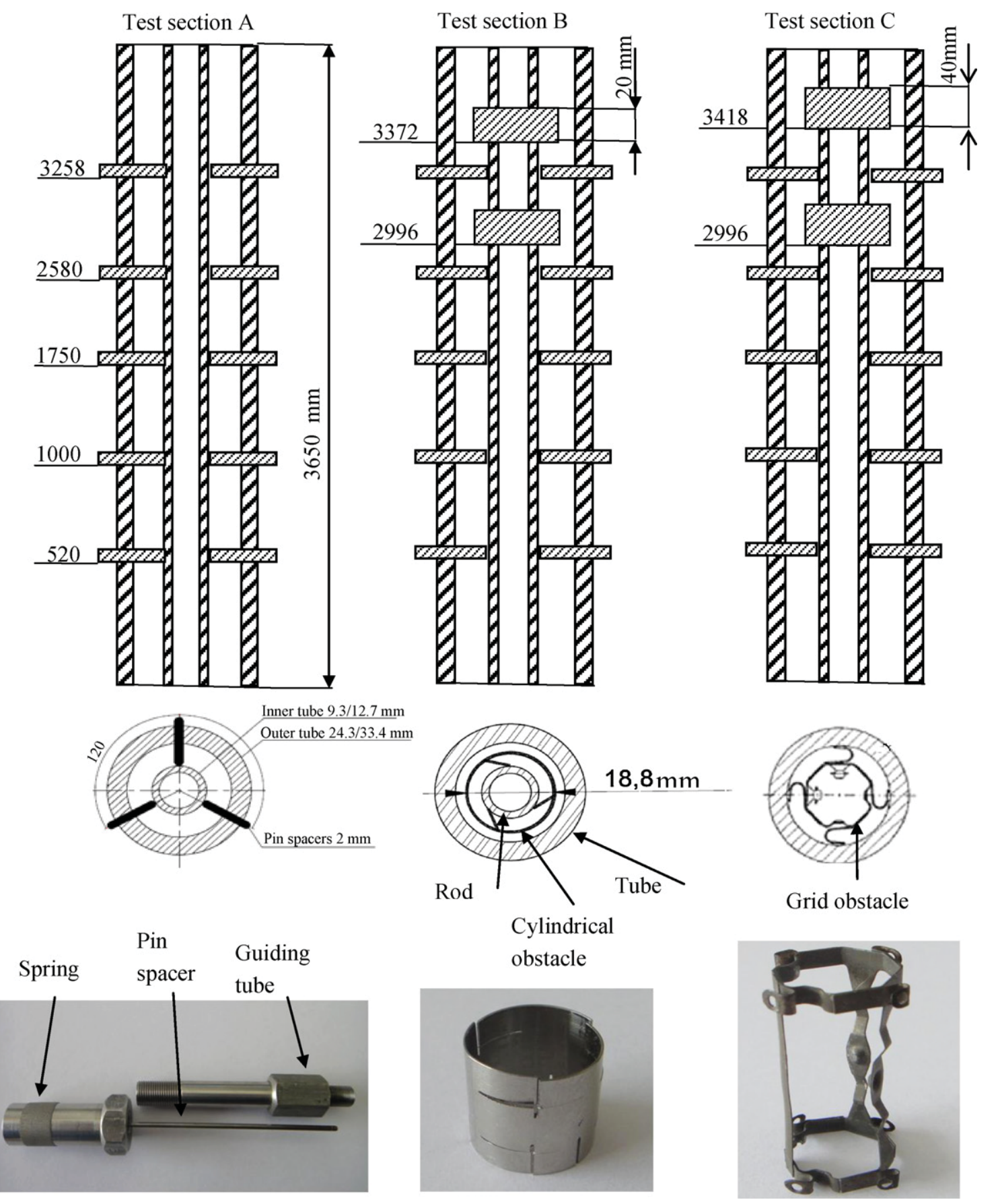

Fig. 2. Test sections employed during experimental runs.

measurements were mounted in wells, $120 \mathrm{~mm}$ deep and $3 \mathrm{~mm}$ in diameter. The measured temperatures are:

- Coolant water temperature from secondary circuit of the circulation pump;

- Coolant water temperature of the primary circuit before pump entrance to avoid cavitations;

- Coolant water temperature of the loop before the flow measurement system that is necessary to calculate viscosity, specific volume and the mass flux;

- Coolant water temperature of the loop after preheater necessary to refine the inlet conditions before test section;

- Coolant water temperatures at inlet and outlet of the test section that are necessary to calculate heat balance before starting two phase flow. The inlet temperature is needed to confirm experimental conditions;

- Coolant water from the secondary circuit of the condenser.

The temperature of the annulus walls were recorded with $88 \mathrm{~K}-$ type thermocouples, 40 located axially on the inside surface of the rod and 48 located on the outside surface of the tube. The present work contains temperature measurements performed on the inside surface of the rod. The thermocouples mounted inside of the rod were arranged in a bundle. One layer of a glass fibre tape and one layer of a mica tape were used to keep the bundle tightened and to insulate and protect the thermocouple heads from the electrically conducting hot surface of the heated walls. The thermocouples were pressed against the wall surface by small springs located in the 


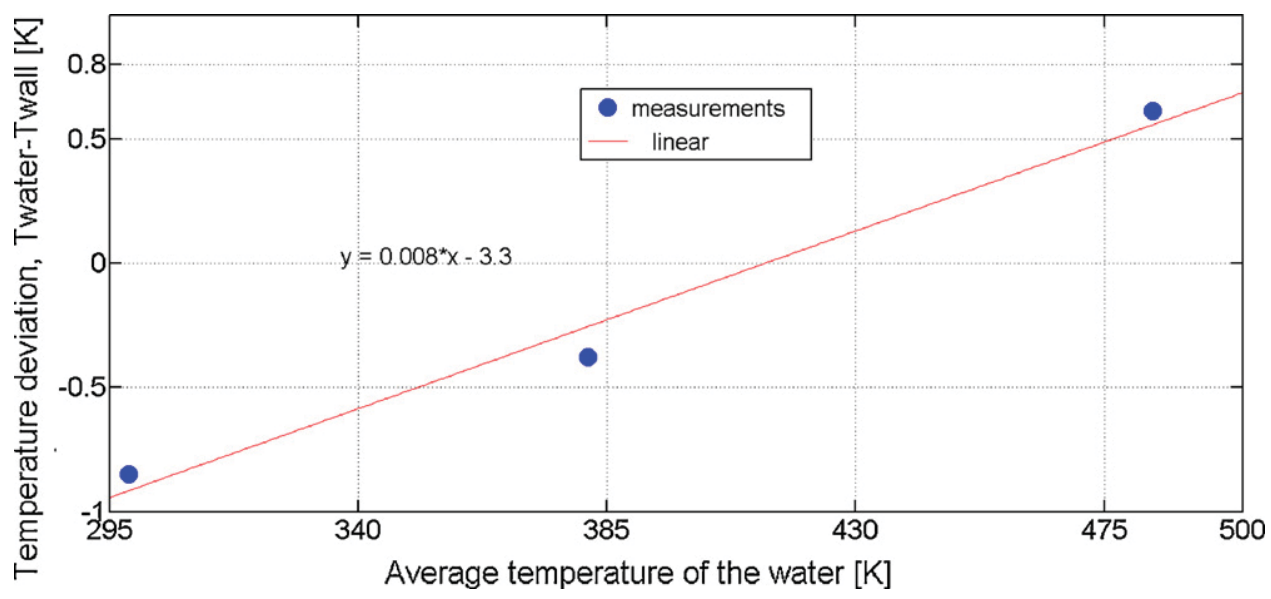

Fig. 3. Temperature deviations for rod.

opposite location on the diagonal. Axial locations of the thermocouples, which are equal to both, the tube and the rod, are presented in Table 1. To correct the readings of the assembled thermocouples at various temperature levels, three experiments were conducted for adiabatic, single phase water flow with inlet temperature equal to 298,383 and $483 \mathrm{~K}$. The wall temperature deviations from the water bulk temperature are presented in Fig. 3.

\subsection{Experimental method}

Each series of experiments was initiated with a measurement of heat balance for single phase flow in the test section. In that way the accuracy of instrumentation was checked. At the beginning of the measurements, to check the accuracy of the instrumentation, the heat balances for single phase flow were performed every time. The temperatures of the liquid measured at the inlet and outlet of the test section were used to determine the enthalpy gain over the heated length. The calculated thermal power was compared with the electrical power output supplied to the test section by the DC generator, by means currents and voltages. If the error were below $0.5 \%$, in the calculations needed for two-phase flow, the electrical power has been used.

The standard method to perform measurements of post-dryout heat transfer includes the following steps:

- for a set of chosen parameters such as the inlet subcooling, the mass flux and the pressure, the power of the heater is set slightly below the level that corresponds to the first occurrence of dryout in the test section,

- the power is increased step-wise (keeping the rest of the parameters constant) and the temperature distribution is recorded once the steady-state condition is achieved. The procedure is repeated for the same inlet conditions, employing all three different kinds of flow obstacles.

Table 1

The thermocouples locations on the rod and tube walls (distance from the beginning of the heated length in millimetres).

\begin{tabular}{llllllllll}
\hline T1 & T2 & T3 & T4 & T5 & T6 & T7 & T8 & T9 & T10 \\
1607 & 1657 & 2225 & 2275 & 2353 & 2452 & 2553 & 2601 & 2616 & 2627 \\
T11 & T12 & T13 & T14 & T15 & T16 & T17 & T18 & T19 & T20 \\
2637 & 2712 & 2767 & 2822 & 2878 & 2933 & 2986 & 2997 & 3004 & 3009 \\
T21 & T22 & T23 & T24 & T25 & T26 & T27 & T28 & T29 & T30 \\
3018 & 3070 & 3107 & 3145 & 3181 & 3219 & 3256 & 3293 & 3329 & 3367 \\
T31 & T32 & T33 & T34 & T35 & T36 & T37 & T38 & T39 & T40 \\
3378 & 3383 & 3389 & 3398 & 3442 & 3475 & 3510 & 3544 & 3588 & 3611 \\
\hline
\end{tabular}

\subsection{Uncertainties}

In the experimental studies, one of the most important issues is to evaluate the accuracy of measurements. The uncertainties in the present study can be classified as follows: uncertainty of a measured parameter, uncertainty of a derived variable due to the propagation of uncertainties of measured variables and uncertainty due to numerical iterations. All measurements of temperatures, pressure, pressure drops, mass flow rates, currents and voltages are subjects to a certain degree of uncertainty:

- Uncertainty of temperature measurements is indicated for standard $\mathrm{K}$ thermocouples class 1 as: $1.5 \mathrm{~K}$ (http://www.omega.co.uk/guides/Thermocouples.html).

- Uncertainty of mass flow rate measurements: $\pm 0.5 \%$ (Flow Technology Inc.).

- Uncertainty of static pressure measurements: $\pm 0.1 \%$.

- During heat balance operation, the electrical power was compared with the enthalpy increase over the test section and the total power uncertainty was estimated as $\pm 0.5 \%$.

The outer wall temperature of the rod and the inner wall temperature of the tube are derived from the conduction equation with volumetric heat sources. The outer surface temperature of the rod is obtained as:

$T_{r_{o}}=T_{r_{i}}+\frac{q_{v}}{2 \lambda}\left(\frac{r_{r_{i}}^{2}-r_{r_{o}}^{2}}{2}-r_{r_{i}}^{2} \ln \frac{r_{r_{i}}}{r_{r_{o}}}\right)$,

where $T_{r_{o}}$ is the wall temperature at the outer (wetted) surface, $T_{r_{i}}$ is the wall temperature at the inner (insulated) surface, $r_{i}$ and $r_{o}$ is the inner/outer radius of the rod and $q_{v}$ is the heat source per unit volume.

The uncertainty of the temperature of the rod outer surface is found as:

$u_{T_{r_{o}}}=\left[\left(\frac{\partial T_{r_{o}}}{\partial T_{r_{i}}} u_{T_{r_{i}}}\right)^{2}+\left(\frac{\partial T_{r_{o}}}{\partial q_{v}} u_{q_{v}}\right)^{2}+\left(\frac{\partial T_{r_{o}}}{\partial \lambda} u_{\lambda}\right)^{2}\right]^{1 / 2}$

where $u_{T_{r i}}$ is the uncertainty of the temperature of the inner rod surface, $u_{q_{v}}$ is the uncertainty of the heat source, $u_{\lambda}$ is the uncertainty of the thermal conductivity of the wall material and $u_{T_{r o}}$ represents the calculated uncertainty of the temperature of the rod outer wall surface. Numerical calculations indicate that this uncertainty is less than $1.53 \mathrm{~K}$, as shown in Fig. 4 for a typical experimental case. 


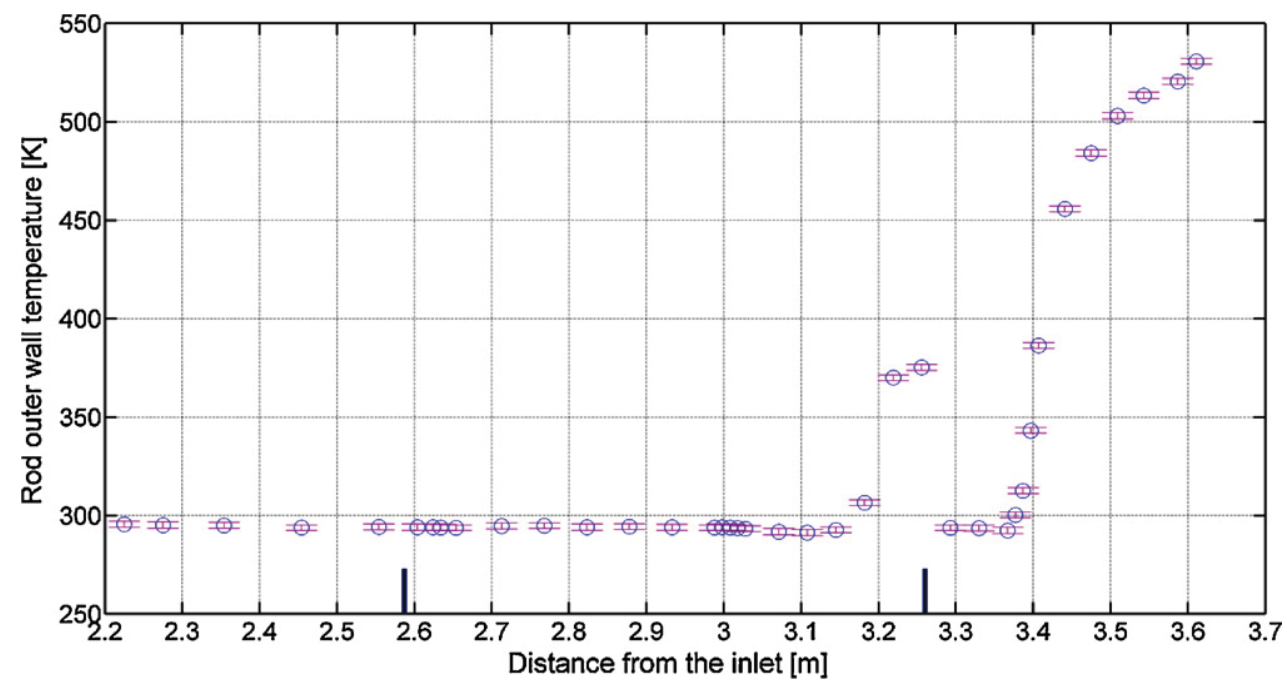

Fig. 4. The rod outer wall temperature with indicated error-bars. Mass flux $G=500 \mathrm{~kg} / \mathrm{m}^{2} \mathrm{~s}$, inlet subcooling $\Delta T=10 \mathrm{~K}$, pressure $P=5 \mathrm{MPa}$, $q^{\prime \prime}=499 \mathrm{~kW} / \mathrm{m}^{2}$, test section A.

\section{Experimental results}

\subsection{General trends}

The present study shows that the influence of flow obstacles on post-dryout heat transfer is quite significant. Their primary effect is to disturb the flow field of the vapour phase which in turn causes an increase of the deposition rate of liquid droplets. The effect however depends on the obstacle shape and its axial location. In this study the net effect of obstacles was investigated by comparing the data obtained in the reference test section (with pins only) and the test section with introduced flow obstacles. The results of runs with three different geometries (test sections A, B and C) are presented in Figs. 5-12. The heat fluxes in case of rod and tube are denoted as $q_{r}$ and $q_{t}$.

A typical development of the dryout patch can be observed in Fig. 5, showing experimental results obtained in test section A. Initial dry patch appears at the exit of the test section when heat flux on the rod surface is equal to $509.7 \mathrm{~kW} / \mathrm{m}^{2}$. After increasing the heat flux to $529.5 \mathrm{~kW} / \mathrm{m}^{2}$, the rod wetted surface superheat at the test section exit increases to almost $300 \mathrm{~K}$. In both cases, the dryout patch is still located downstream of the last level of pin spacers. When the heat flux is slightly increased to $529.9 \mathrm{~kW} / \mathrm{m}^{2}$, a second dryout patch is developed upstream of the last pin spacer position. In this case, the effect of the pin spacer is very clear: the dry patch is quenched just downstream of the pin spacer and the surface superheat is reduced to the values which are typical for the pre-dryout conditions. In the last experimental run, the heat flux was increased to $534.3 \mathrm{~kW} / \mathrm{m}^{2}$. As a consequence wall superheat increased to $250 \mathrm{~K}$ upstream of the last pin spacer location. Due to the turbulence induced by the pin spacer, the liquid film was remade and the annular flow regime was restored for approximately $50 \mathrm{~mm}$.

\subsection{Influence of the cylindrical obstacle}

The net effect of the cylindrical obstacle can be seen by comparing the measured wall superheat shown in Figs. 5 and 6. As shown in Fig. 6, the first appearance of a dry patch takes place at the exit of the test section when the heat flux at the rod surface is equal

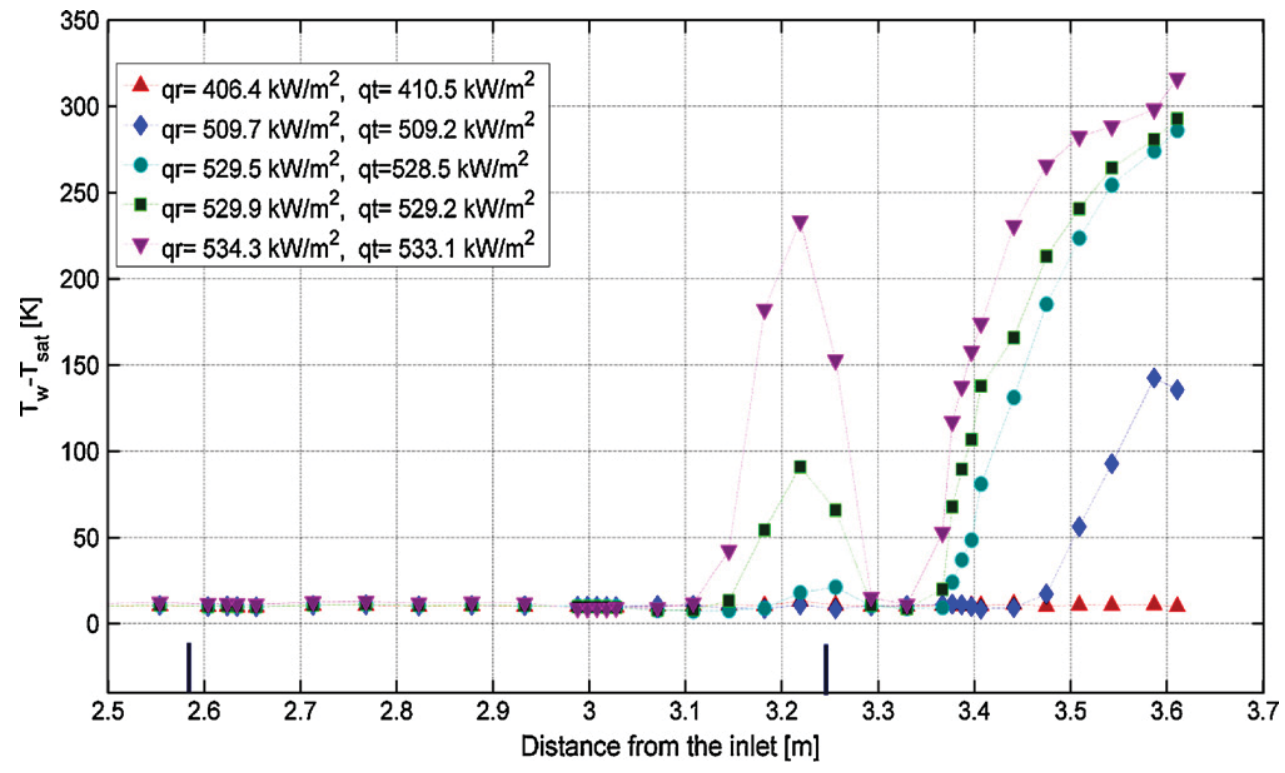

Fig. 5. Measured superheat of rod wall surface for various heat fluxes. Mass flux $G=500 \mathrm{~kg} / \mathrm{m}^{2} \mathrm{~s}$, inlet subcooling $\Delta T=10 \mathrm{~K}$, pressure $P=5 \mathrm{MPa}$, test section $\mathrm{A}$. 


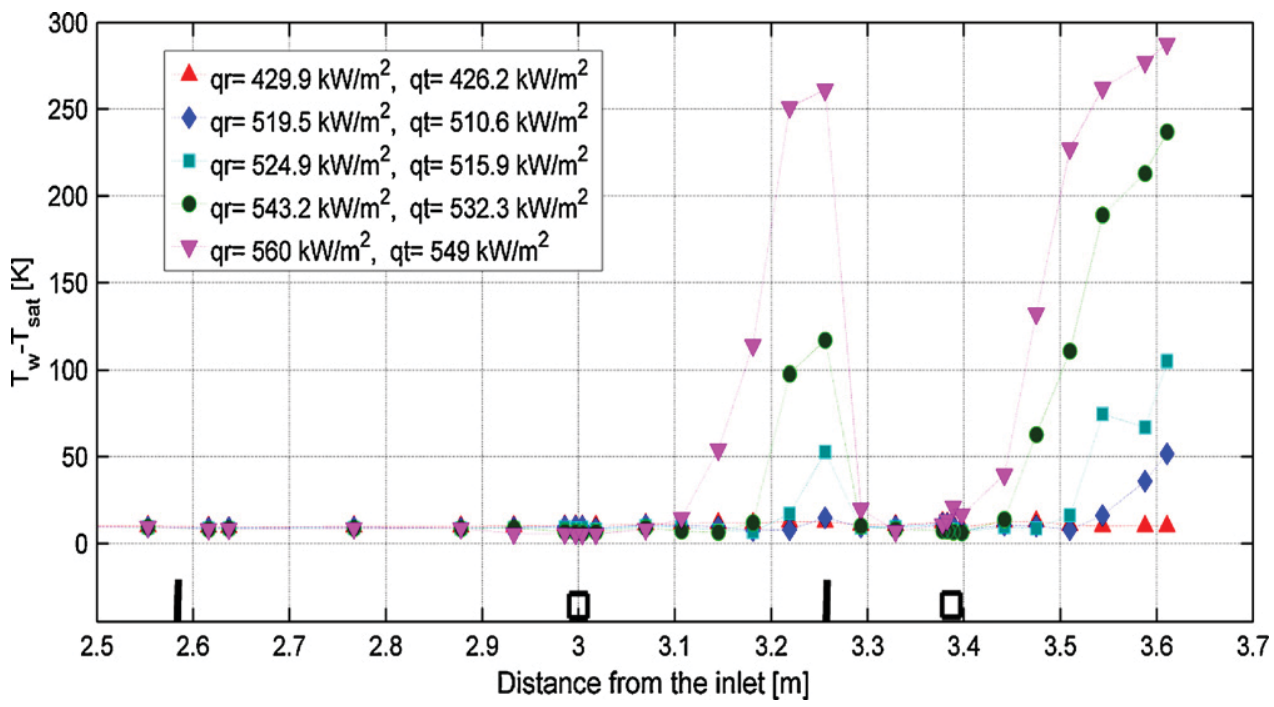

Fig. 6. Measured superheat of rod wall surface for various heat fluxes. Mass flux $G=500 \mathrm{~kg} / \mathrm{m}^{2} \mathrm{~s}$, inlet subcooling $\Delta T=10 \mathrm{~K}$, pressure $P=5 \mathrm{MPa}$, test section B.

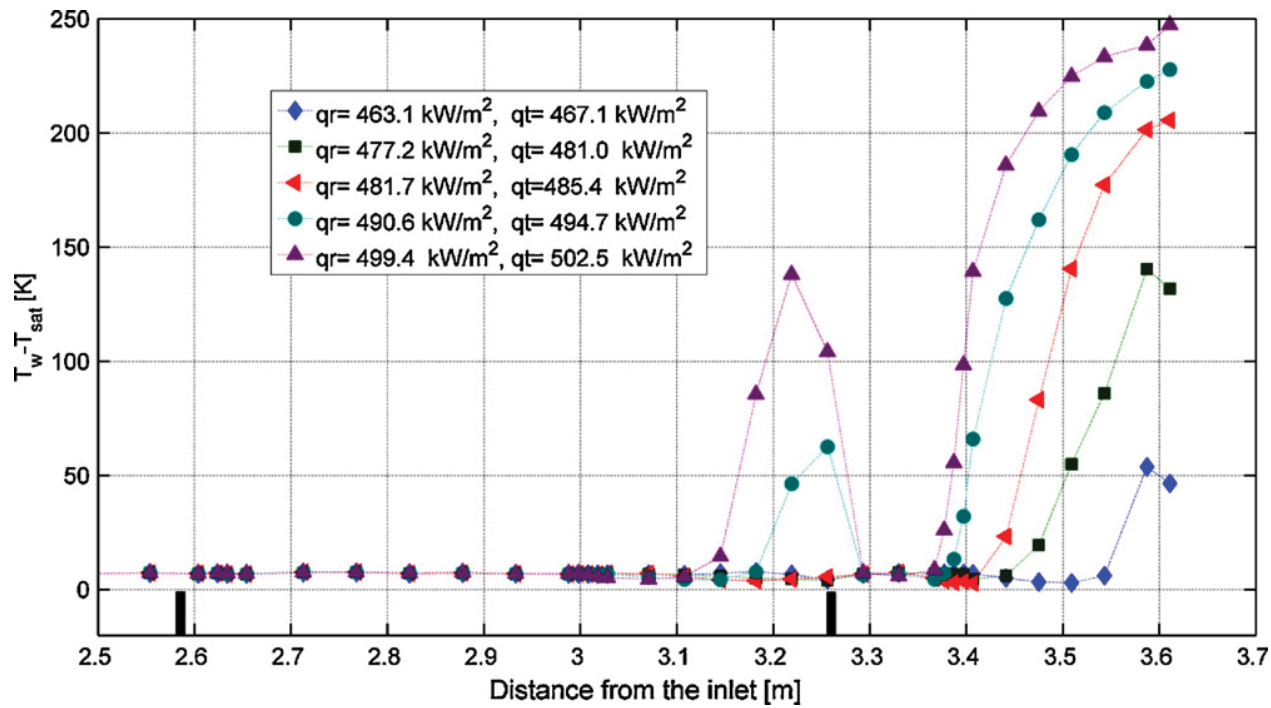

Fig. 7. Measured superheat of rod wall surface for various heat fluxes. Mass flux $G=500 \mathrm{~kg} / \mathrm{m}^{2} \mathrm{~s}$, inlet subcooling $\Delta T=10 \mathrm{~K}$, pressure $P=7 \mathrm{MPa}$, test section A.

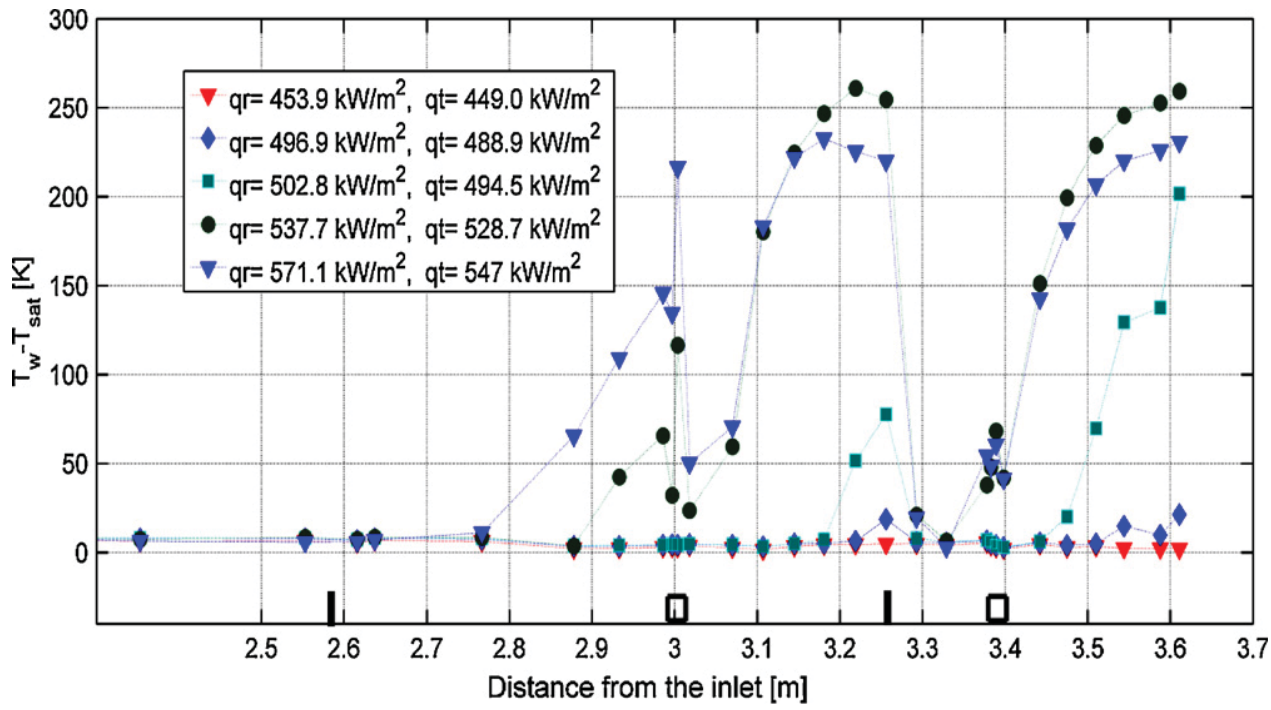

Fig. 8. Measured superheat of rod wall surface for various heat fluxes. Mass flux $G=500 \mathrm{~kg} / \mathrm{m}^{2} \mathrm{~s}$, inlet subcooling $\Delta T=10 \mathrm{~K}$, pressure $P=7 \mathrm{MPa}$, test section B. 


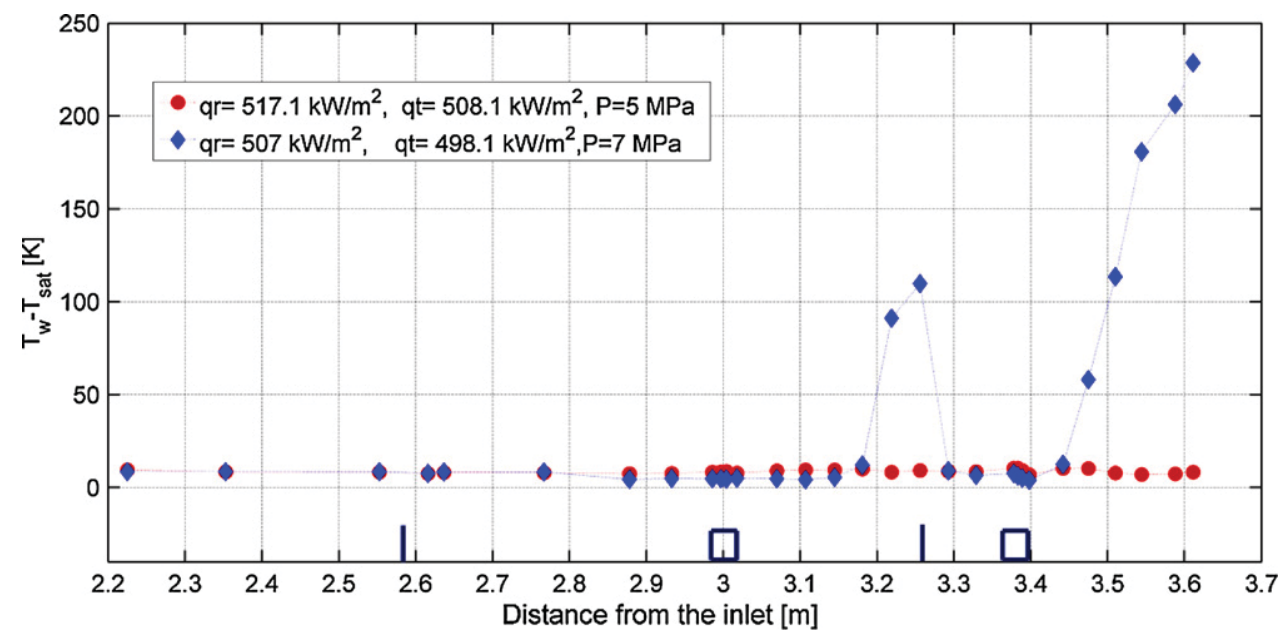

Fig. 9. Measured superheat of rod wall surface for various heat fluxes. Mass flux $G=500 \mathrm{~kg} / \mathrm{m}^{2} \mathrm{~s}$, inlet subcooling $\Delta T=10 \mathrm{~K}$, pressure $P=5-7 \mathrm{MPa}$, test section $\mathrm{B}$.

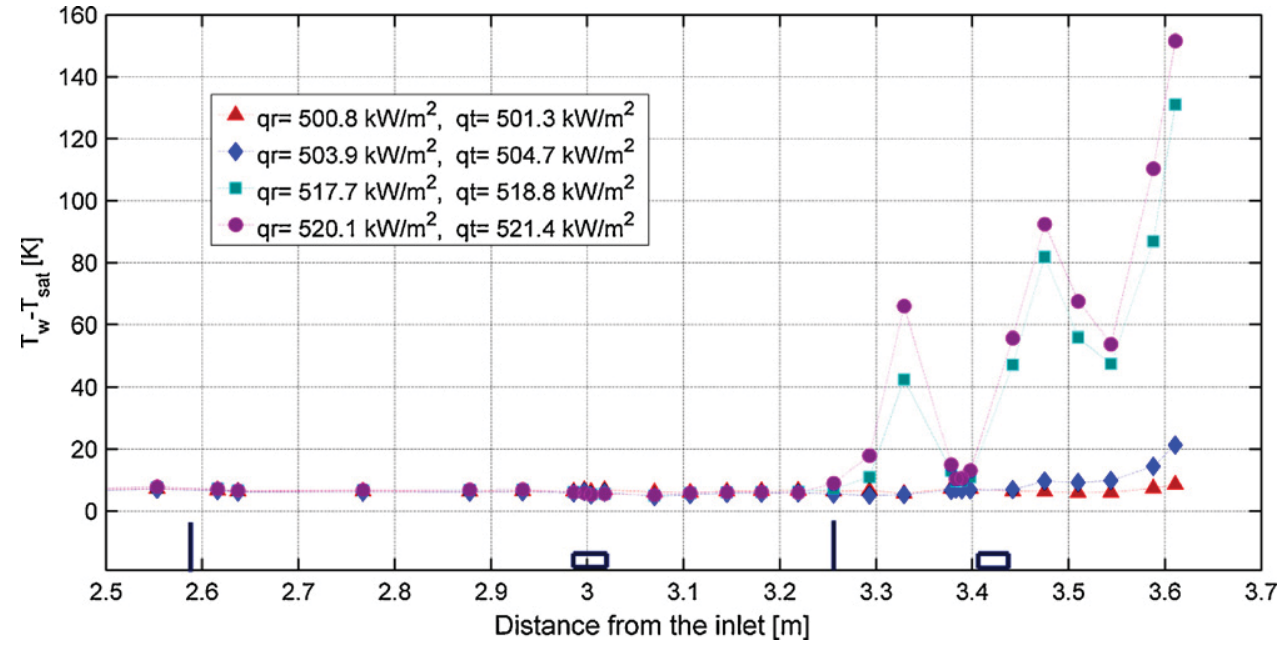

Fig. 10. Measured superheat of rod wall surface for various heat fluxes. Mass flux $G=500 \mathrm{~kg} / \mathrm{m}^{2} \mathrm{~s}$, inlet subcooling $\Delta T=10 \mathrm{~K}$, pressure $P=7 \mathrm{MPa}$, test section $\mathrm{C}$.

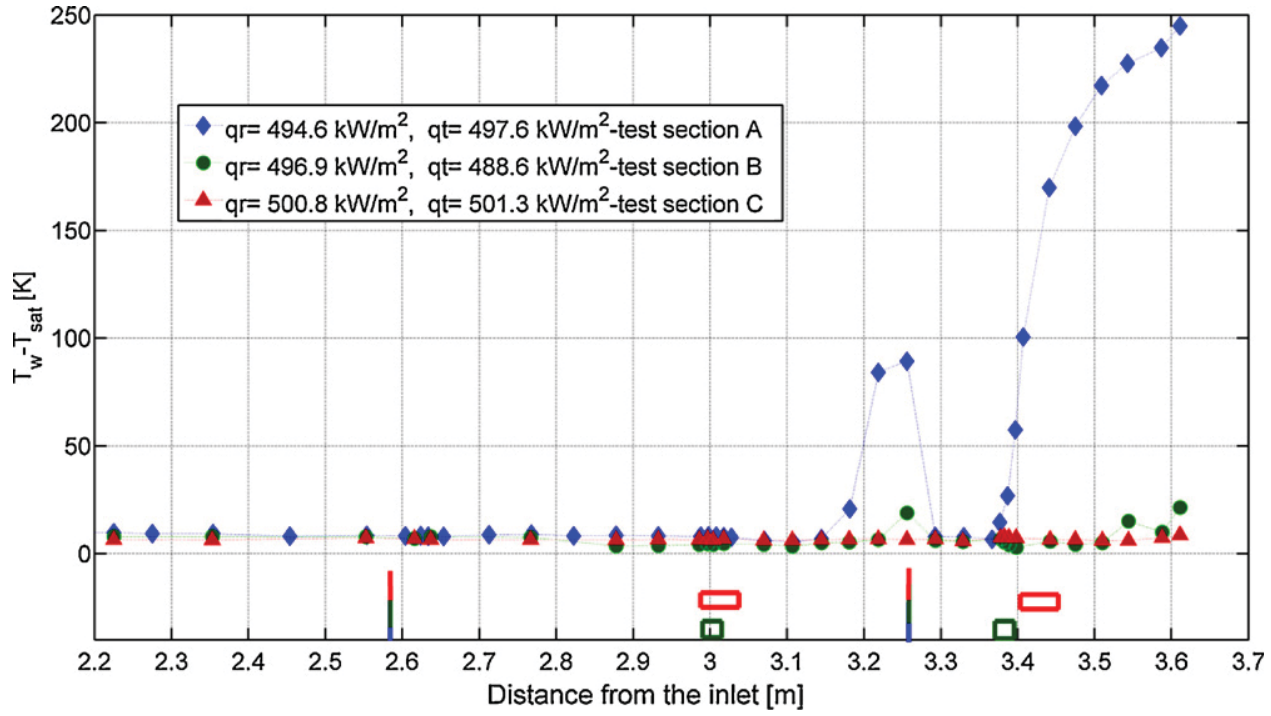

Fig. 11. Measured superheat of rod wall surface for various heat fluxes. Mass flux $G=500 \mathrm{~kg} / \mathrm{m}^{2} \mathrm{~s}$, inlet subcooling $\Delta T=10 \mathrm{~K}$, pressure $P=7 \mathrm{MPa}$. 


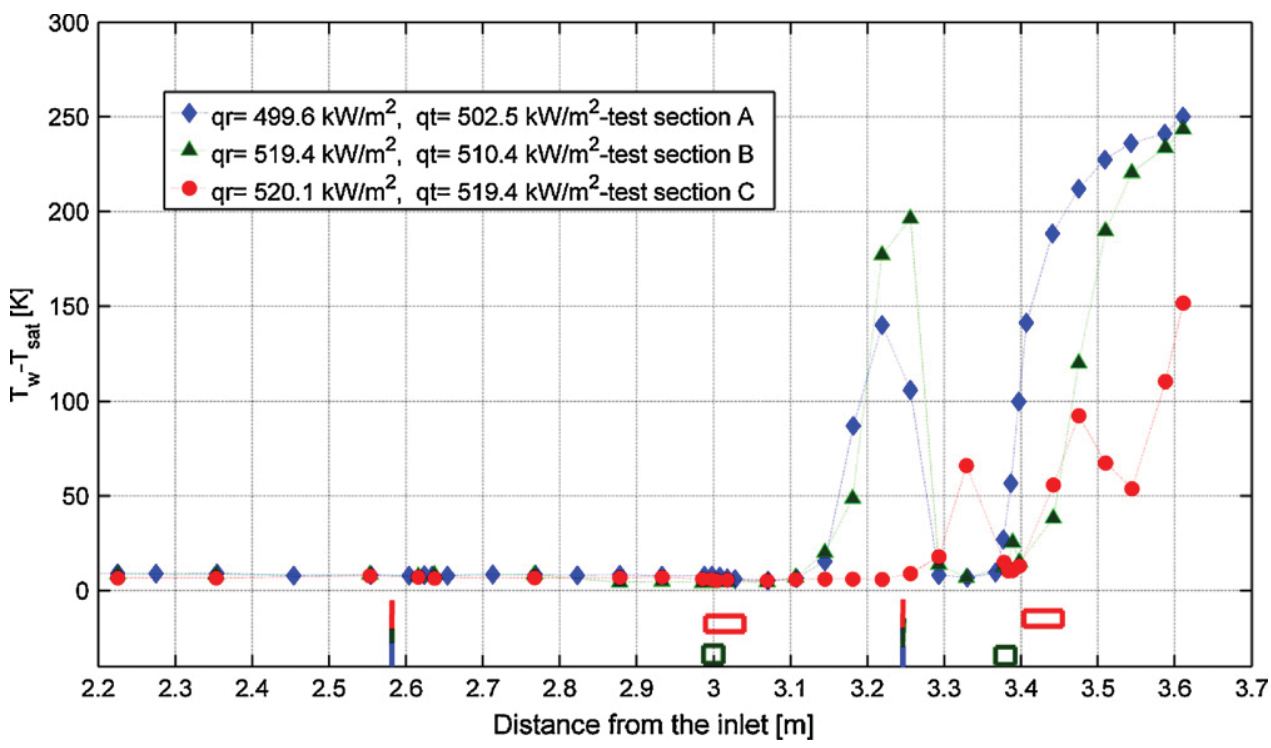

Fig. 12. Measured superheat of rod wall surface for various heat fluxes. Mass flux $G=500 \mathrm{~kg} / \mathrm{m}^{2} \mathrm{~s}$, inlet subcooling $\Delta T=10 \mathrm{~K}$, pressure $P=7 \mathrm{MPa}$.

to $519.5 \mathrm{~kW} / \mathrm{m}^{2}$, and the measured maximum wall superheat is equal to $50 \mathrm{~K}$. In test section $\mathrm{A}$, which has pin spacers only, the wall superheat is about $150 \mathrm{~K}$ at slightly lower heat flux equal to $509.7 \mathrm{~kW} / \mathrm{m}^{2}$. This result indicates that insertion of the cylindrical flow obstacle both increases the critical power level and decreases the wall superheat, as expected. This effect can be explained by increase of the deposition rate of droplets caused by the cylindrical flow obstacle.

When the heat flux on the rod surface is increased to $524.9 \mathrm{~kW} / \mathrm{m}^{2}$, a second dry patch appears just upstream of the last pin spacer. This dry patch slightly grows in the upstream direction when the rod surface heat flux is further increased to 543.2 and $560 \mathrm{~kW} / \mathrm{m}^{2}$. From Fig. 5 it can be seen that the onset of dryout occurs at approximately $3.1 \mathrm{~m}$ from the beginning of heated length, when the heat flux on the rod surface is equal to $534.3 \mathrm{~kW} / \mathrm{m}^{2}$. The onset of dryout point is moved about $80 \mathrm{~mm}$ downstream when the cylindrical obstacle is inserted and the heat flux on the rod surface is increased to $543.2 \mathrm{~kW} / \mathrm{m}^{2}$.

Figs. 7 and 8 show the effect of the cylindrical obstacle at system pressure equal to $7 \mathrm{MPa}$, whereas. It can be seen, that insertion of the cylindrical flow obstacles increases the critical heat flux from about $463.1 \mathrm{~kW} / \mathrm{m}^{2}$ to $496.9 \mathrm{~kW} / \mathrm{m}^{2}$. It is interesting to note that for the heat flux higher than $537.7 \mathrm{~kW} / \mathrm{m}^{2}$, the cylindrical obstacle is causing a temperature drop just downstream of its location, however, full quenching of a dry patch is not taking place. On the contrary, a full quenching of a dry patch is caused by the last pin spacer. This indicates that pin spacers are more effective in rebuilding the liquid film than the cylindrical obstacles.

Fig. 9 shows the effect of pressure on heat transfer and the occurrence of dryout in test section with the cylindrical obstacles. As can be seen, the post-dryout regime prevails at pressure $7 \mathrm{MPa}$, whereas no dryout occurs at pressure $5 \mathrm{MPa}$, even though the heat flux on the rod surface is higher in the latter case.

\subsection{Influence of the grid obstacle}

The effect of the grid obstacle can be seen in Fig. 10 in comparison with Fig. 7. The figures show the measured wall superheat for increasing power at system pressure equal to $7 \mathrm{MPa}$. The insertion of the grid flow obstacles increases the critical heat flux from about $463.1 \mathrm{~kW} / \mathrm{m}^{2}$ to $503.9 \mathrm{~kW} / \mathrm{m}^{2}$. This result indicates that grid spacers are slightly more efficient in preventing dryout than the cylindri- cal obstacles. A plausible explanation of this difference may be the higher blockage ratio of the grid obstacle causing higher turbulence level and thus higher deposition rate of droplets downstream of the obstacle.

Direct comparisons of the experimental results obtained in all three test sections are shown in Figs. 11 and 12. Fig. 11 shows the results obtained in the three test section at almost the same operational conditions, with heat flux on the rod surface in a range from 494.6 to $500.8 \mathrm{~kW} / \mathrm{m}^{2}$. The shown results correspond to fully developed post-dryout conditions in test section A, onset of dryout in test section $B$ and pre-dryout conditions in test section C. Fig. 12 shows the measured rod surface superheat for the three test section at fully developed post-dryout conditions. It can be seen that the lowest wall superheat is measured in test section C, even though the applied power is the highest.

\section{Summary and conclusions}

New measurements of post-dryout heat transfer in annuli with various flow obstacles have been presented. The experiments have been performed with water as working fluid at pressures 5 and $7 \mathrm{MPa}$, inlet mass flux $500 \mathrm{~kg} / \mathrm{m}^{2} \mathrm{~s}$ and inlet sub-cooling $10 \mathrm{~K}$. A thorough analysis of experimental uncertainties has been performed to provide accurate data that can be used for validation of computational models. A high spatial resolution in the measurements has been obtained by placing 88 thermocouples along test sections, from which 40 thermocouples have been placed inside of the heated rod.

The net effects of the cylindrical and grid flow obstacles have been measured by using a reference test section where only pin spacers were used to support the central rod. It is concluded that flow obstacles improve over-all critical power in test sections. This effect seems to depend on the obstacle location, shape and blockage ratio. In post-dryout regime the obstacles either quench the dry patch downstream of their location, or reduce the wall temperature.

\section{Acknowledgment}

The financial support provided by Swedish Centre for Nuclear Technology (SKC) is gratefully acknowledged. 


\section{References}

Anghel, I.G., Anglart, H., Hedberg, S., 2010. Study of post dryout heat transfer in annulus with flow obstacles. In: Proc. 14th International Heat transfer Conference, IHTC-14, Washington, USA.

Anglart, H., Persson, P., 2007. Experimental investigation of post-dryout heat transfer with spacers. Int. J. Multiphase Flows 33 (8), 809-821.

Flow Technology Inc., CA03-User Manual.

Inconel 600 detailed technical report. Available from: <http://www.haraldpihl. se/engelsk/index.html>.
Koizumi, Y., Kumamaru, H., Yonomoto, T., Tasaka, K., 1987. Post-dryout heat transfer of high-pressure steam-water two-phase flow in single rod channel and multi rod bundle. Nucl. Eng. Des. 99, 157-165.

Moon, S.-K., Chun, S.-Y., Cho, S., 2005. An experimental study of post-CHF heat transfer for low flow of water in a $3 \times 3$ rod bundle. Nucl. Eng. Technol. 37 . 457-468.

Tuzla, K., Unal, C., Chen, J.C., 1992. An experimental study of post-CHF heat transfer in a $3 \times 3$ rod bundle. In: Hewitt, G.F., Delhaye, J.M., Zuber, N. (Eds.), Multiphase Science and Technology, Post-Dryout Heat Transfer. CRC Press. 